\title{
Substâncias Químicas, Riscos Industriais e Ambiente
}

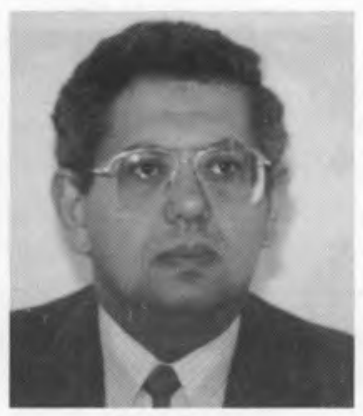

Rui F. Simões

Engenheiro pelo IST / UTL

Técnico superior da Direcção Geral da Qualidade do Ambiente. Ex-docente convidado do IST.

Ex-estagiário da Direcçâo Geral do Ambiente da Comissão da Comunidade Europeia (Bruxelas), nas áreas de integração europeia, riscos químicos e segurança ambiental.

Actividade profissional na Administração Central no âmbito do controlo técnico-administrativo da actividade industrial e da legislação e regulamentação sobre segurança industrial e controlo da poluição, nas áreas da qualidade industrial, saúde e segurança do trabalho, segurança industrial e qualidade do ambiente.

Trabalhos publicados sobre controlo da poluição atmosférica, gestão de resíduos e riscos tecnológicos graves.

Actividade técnica actual centrada na implementação da política de prevenção de riscos de acidentes ambientais tecnológicos graves / prevenção e controlo de acidentes industriais graves. Membro da Autoridade Técnica de Riscos Industriais Graves, em representação da Direcçâo Geral da Qualidade do Ambiente.

Delegado, por Portugal, ao Comité Europeu das Autoridades Nacionais Competentes para a Aplicação da Directiva Comunitária 82/501/CEE (Bruxelas, Direç̧ão Geral XI Ambiente/Substâncias Químicas e Riscos Industriais) e ao Grupo de Peritos sobre Acidentes Envolvendo Substâncias Perigosas (OCDE, Paris).

\section{Introdução}

Encontram-se comercializadas mais de 100000 substâncias químicas.

De entre estas, cerca de 10000 revestem grande importância do ponto de vista da produção ou utilização a nível industrial. Estes números traduzem a dimensão dos problemas postos pela produção, emprego, transporte, utilização e eliminação das substâncias químicas perigosas.

Até muito recentemente o uso indiscriminado de substâncias químicas era aceite passivamente, muitas vezes sem o conhecimento das suas propriedades e sem a identificação e avaliação, aos diferentes níveis, dos perigos e riscos associados.

Tal tem suscitado situações tão diversas quanto antagónicas: se por um lado se enfatizaram os benefícios decorrentes da sua utilização sem ter em conta as suas consequências, por outro lado, a insuficiência das medidas de prevenção previstas permitiu a ocorrência de acidentes químicos, alguns de consequências extremamente gravosas (Seveso, Bhopal, Basileia).

A tomada de consciência da natureza e da amplitude dos problemas tem levado os governos e as próprias instâncias comunitárias a uma acção mais adequada à especificidade dos perigos e riscos em presença.

Vamos nestas notas explicitar a acção comunitária no domínio do ambiente no âmbito das substâncias químicas perigosas e dos riscos industriais graves e referir o correpondente quadro legislativo nacional.

\section{Comunidade Europeia: acção no domínio das substâncias perigosas}

A Comissão da Comunidade Europeia desenvolve, através da sua Direcção Geral do Ambiente, acções no domínio do controlo das substâncias químicas e dos riscos industriais, de entre as quais salientamos:

EINECS: um inventário europeu de substâncias perigosas, elaborado a nível comunitário (já publicada a versão em inglês: «European Inventory of Existing Chemical Substances»); 
Programa relativo às substâncias químicas existentes: recolha de informações sobre as substâncias comercializadas no mercado europeu e avaliação dos riscos que elas podem apresentar para o homem e o ambiente;

Rotulagem de substâncias perigosas: normalização dos símbolos indicadores de perigos apresentados por cada substância, explicitando todo um conjunto de informação relativa a riscos específicos e a conselhos de prudência (cerca de 1200 substâncias foram já classificadas e etiquetadas a nível comunitário, das quais 80 cancerígenas);

Ensaio e controlo de novas substâncias químicas: um sistema de notificação obriga os produtores a fornecerem às respectivas autoridades nacionais competentes um dossier contendo informações sobre ensaios físico-químicos, toxicológicos e ecotoxicológicos normalizados, bem como uma adequada avaliação de riscos para o homem e o ambiente de todas as novas substâncias químicas;

Protecção da camada de ozono: a legislação comunitária impõe o controlo da produção e utilização dos CFC's e halons responsáveis pela depleção da camada de ozono;

Cádmio: a Comissão desenvolveu um programa de acção comunitário para combater a poluição ambiental provocada pelo cádmio;

Directiva sobre acidentes industriais graves (aig's): estabelecendo objectivos e metodologias comuns respeitantes à prevenção, controlo e limitação das consequências dos riscos externos graves associados a certas actividades industriais, impondo obrigações tanto para os industriais como para os Estados membros.

Para além da obrigatoriedade de identificação de perigos e avaliação dos riscos de acidentes industriais graves e da adopção das adequadas medidas de prevenção e de mitigação, a Directiva estipula a obrigatoriedade da informação das populações do comportamento a adoptar em caso de ocorrência de um aig.

A estas acções e iniciativas da Comissão corresponde um conjunto de actos de direito comunitário derivado aprovados em Conselho Comunitário de Ministros do Ambiente, dos quais, a título ilustrativo, se apresenta uma selecção no Quadro I.

\section{Portugal: prevenção de riscos químicos ambientais}

A Lei de Bases do Ambiente define os princípios da política de ambiente em Portugal. Várias são já as disposições regulamentares particulares publicadas nas várias áreas de preocupação específicas no âmbito do ambiente.

Apresentamos no Quadro II uma listagem das disposições legislativas nacionais mais relevantes, nesta área da prevenção dos riscos químicos versus ambiente.

Referir-nos-emos, em particular, a duas delas:

\section{Decreto-Lei $280-A / 87$}

Este diploma institui um sistema obrigatório de notificação aplicável sempre que uma nova substância vier a ser comercializada, por um produtor nacional ou por um importador. Pretende-se, assim, o conhecimento antecipado das carac- terísticas de perigosidade das novas substâncias, de modo a permitir uma adequada avaliação dos riscos.

Neste sistema comunitário, a entidade nacional de notificação é a Direcção Geral da Qualidade do Ambiente, a quem terão de ser submetidos os dossiers de notificação, instruídos com as necessárias informações sobre as propriedades das novas substâncias e propostas de classificação, rotulagem e medidas de segurança.

Por outro lado, o Decreto-Lei 280-A/87, estipula regras comuns para a classificação e rotulagem das substâncias perigosas com vista à protecção dos trabalhadores, consumidores em geral e do ambiente, com indicação da adequada informação sobre os perigos associados.

O diploma estabelece o conteúdo dos rótulos, suas dimensões e outros requisitos.

Em anexo consta uma lista com mais de 1000 substâncias perigosas classificadas, sendo para cada uma delas indicado a respectiva categoria e símbolo gráfico de perigo, as frases relativas aos riscos e as frases respeitantes a conselhos de prudência que devem constar dos rótulos.

Este diploma encontra-se adaptado ao progresso técnico pelo Decreto-Lei nº 124/88, de 1988.04.20.

\section{Decreto-Lei $224 / 87$}

O Decreto-Lei 224/87 aplica-se a certas actividades industriais, que requerem que seja dedicada particular atenção aos aspectos de protecção das populações e do ambiente, no que respeita à prevenção e minimização dos potenciais acidentes de consequências graves para o exterior.

$\mathrm{O}$ diploma estabelece que os industriais identifiquem os perigos e avaliem os riscos de acidentes industriais graves, prevejam as medidas adequadas ao nível do projecto e da laboração e adoptem as medidas necessárias para minimizar as consequências dos eventuais acidentes associados aos riscos residuais.

Nos casos dos estabelecimentos industriais - laboração ou armazenagem separada - de mais alto risco o industrial é obrigado a evidenciar de forma objectiva, através da submissão à autoridade competente de uma Notificação, que alcançou os desideratos pretendidos.

Esta Notificação da Segurança deve ser constituída por um Estudo de Segurança Aprofundado (contendo a cenarização dos possíveis acidentes graves) e pelo respectivo plano de emergência interno.

Do Estudo de Segurança Aprofundado deve constar a descrição do estabelecimento, a identificação dos perigos internos e externos e caracterização dos riscos e o estudo dos cenários de acidentes industriais graves.

A autoridade nacional criada para o efeito é a Autoridade Técnica de Riscos Industriais Graves (ATRIG), funcionando na dependência do membro do Governo responsável pelo ambiente.

Cabe à ATRIG apreciar as Notificações da Segurança, apreciar tecnicamente os acidentes graves obrigatoriamente comunicados pelos industriais e assegurar que a informação às populações e o respectivo planeamento de emergência é efectuada pelas autoridades competentes de protecção civil. 


\section{QUADRO I}

Directivas Comunitárias no âmbito das substâncias químicas perigosas e ambiente (listagem indicativa)

67/548/CEE relativa à aproximação das disposições legislativas, regulamentares e administrativas respeitantes à classificação, embalagem e rotulagem de substâncias perigosoas, e respectivas modificações e adaptações aos progressos técnicos;

73/173/CEE relativa à aproximação das disposições legislativas, regulamentares e administrativas dos Estados-membros respeitantes à classificação, embalagem e rotulagem de preparações perigosas (solventes) e respectivas modificações;

75/439/CEE relativa à eliminação dos óleos usados e respectivas modificações;

76/464/CEE relativa à poluição causada por determinadas substâncias perigosas lançadas no meio aquático da Comunidade;

77/228/CEE relativa à aproximação das disposições legislativas, regulamentares e administrativas dos Estados-membros respeitantes à classificação, embalagem e rotulagem de tintas, vernizes, tintas de imprensa, colas e produtos conexos e respectivas modificações;

78/319/CEE relativa aos resíduos tóxicos e perigosos;

78/631/CEE relativa à aproximação das disposições legislativas, regulamentares e administrativas dos Estados-membros respeitantes à classificação, rotulagem e embalagem de substâncias perigosas (pesticidas) e respectivas modificações;

80/779/CEE relativa aos valores-limite e aos valores padrão da qualidade do ar para o dióxido de enxofre e partículas em suspensão e respectivas modificações;

$82 / 176 /$ CEE relativa aos valores-limite e aos objectivos de qualidade para as descargas de mercúrio do sector da electrólise dos cloretos alcalinos;

$82 / 501 /$ CEE

$83 / 513 / \mathrm{CEE}$ relativa aos riscos de acidentes graves de certas actividades industriais e respectivas modificações;

relativa aos valores-limite e aos objectivos de qualidade para as descargas de cádmio;

$84 / 156 /$ CEE relativa aos valores-limite e aos objectivos de qualidade para as descargas de mercúrio de sectores que não o da electrólise dos cloretos alcalinos; relativa à luta contra a poluição atmosférica provocada por instalações industriais;

$84 / 360 /$ CEE

84/419/CEE

relativa aos limites e aos objectivos de qualidade para as descargas de hexaclorociclohexano;

$84 / 613 / \mathrm{CEE}$

$85 / 203 / \mathrm{CEE}$

relativa à vigilância e ao controlo na Comunidade das transferências transfronteiras de resíduos perigosos e suas modificações;

$86 / 280 /$ CEE

relativa às normas de qualidade do ar para o dióxido de azoto;

relativa aos valores-limite e aos objectivos de qualidade para as descargas de certas substâncias perigosas incluídas na Lista I do anexo da Directiva 76/464/CEE;

87/017/CEE relativa à aproximação das disposições legislativas, regulamentares e administrativas respeitantes à aplicação de princípios de boas práticas de laboratório e ao controlo da sua aplicação para o ensaio sobre substâncias químicas;

88/379/CEE relativa à aproximação das disposições legislativas, regulamentares e administrativas dos Estados-membros respeitantes à classificação , embalagem e rotulagem das preparações perigosas.

\section{QUADRO II}

Principais disposiçôes legislativas e regulamentares no domínio das substâncias químicas perigosas e do ambiente

\section{SUBSTÂNCIAS QUÍMICAS}

Decreto-Lei nº280-A/87, de 1987.07.17, que estabelece medidas relativas à notificação de substâncias químicas e à classificação, embalagem e rotulagem de substâncias perigosas.

Decreto-Lei $\mathrm{n}^{\circ} 124 / 88$, de 1988.04.20, que altera e actualiza o Decreto 280-A/87.

Decreto-Lei ${ }^{\circ}$ 46-A89, de 1989.02.20, que actualiza os anexos do Decreto-Lei 280-A/87.

Decreto-Lei nº 28/87, de 1987.01.04, que limita a comercialização e utilização do amianto e dos produtos que o contêm.

Decreto-Lei nº 138/88, de 1988.04.22, que estabelece a proibição da comercialização e da utilização de produtos contendo fibras de amianto. Decreto-Lei nº221/88, de 1988.06.28, que limita a comercialização e utilização de algumas substâncias perigosas (PCbs, PCTs e preparações). Decreto-Lei n²293/88, de 1988.06.28, que proibe a utilização de determinados produtos fitofarmacêuticos.

Decreto-Lei nº294/88, de 1988.08.24, que estabelece normas relativas à classificação, rotulagem e embalagem de pesticidas e adjuvantes.

\section{RISCOS AMBIENTAIS GRAVES (TECNOLÓGICOS)}

Decreto-Lei nº 224/87, de 1987.06.03, que estabelece normas relativas à prevenção dos riscos de acidentes graves que possam ser causados por certas actividades industriais, bem como a limitação das suas consequências para o homem e o ambiente.

\section{RESÍDUOS}

Decreto-Lei nº 216/85, de 1985.06.28, que estabelece normas sobre o enquadramento das actividades de armazenagem, recolha e queima de óleos usados.

Decreto-Lei ${ }^{\circ}$ 488/85, de 1985.11.25, que estabelece normas sobre resíduos.

Portaria n³74/87, de 1987.05.04, que aprova o Regulamento sobre Resíduos Originados na Indústria Transformadora.

\section{QUALIDADE DO AR}

Despacho Normativo nº 29/87, de 1987.03.20, que estabelece os limites de concentração de poluentes na atmosfera, adequados à protecção da saúde e do ambiente. 


\section{Referências}

- ATRIG - Notificação da Segurança - Conteúdo Esquemático de Orientação para a sua Apreciação. Autoridade Técnica de Riscos Industriais Graves. Lisboa, 1989.

- ATRIG - Senhor Industrial: Se a sua empresa está abrangida pelo DecretoLei 224/87, de 3 de Junho, Sabe o que fazer em caso de ocorrência de um acidente industrial grave?. ATRIG. Lisboa. 1989.

- COMISSÃO DAS COMUNIDADES EUROPEIAS - Chemical Risk Control in the European Community. Bruxelas. 1987.
- COMISSÃO DAS COMUNIDADES EUROPEIAS - La Communauté Europeenne Face aux Risques d'Accidents Majeurs. Bruxelas. 1988.

- DIRECÇÃO GERAL DA QUALIDADE DO AMBIENTE - Guia para Industriais, Produtores e Importadores de Produtos Químicos. DGQA. Lisboa, 1988.

- JONHSON, S.; CORCELLE, G. - L'Autre Europe «Verte»: La Politique Communautaire de l'Environnement. Labor. Bruxelas. 1987.

- SIMÕES, R. F. - A Directiva Comunitária Pós Seveso. «Segurança», (88), ano XXII, $3^{\circ}$ trimestre, 1987.

- SIMÕES, R: F: - A Directiva Comunitária Pós Seveso: Sua Aplicação em Portugal. In: Livro doas VI Jornadas do Ambiente. 1988.

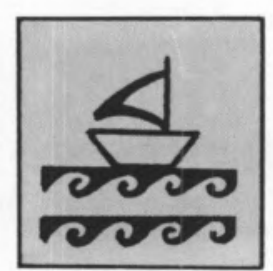

Exxon teve de dispender $\$ 1,28$ biliões, dez vezes mais do que o previsto, para limpar os 50 milhões de litros de crude que o super-petroleiro "Exxon Valdez" derramou em Prince William Sound, no Alasca, no passado mês de Março.

Time, Agosto 1989
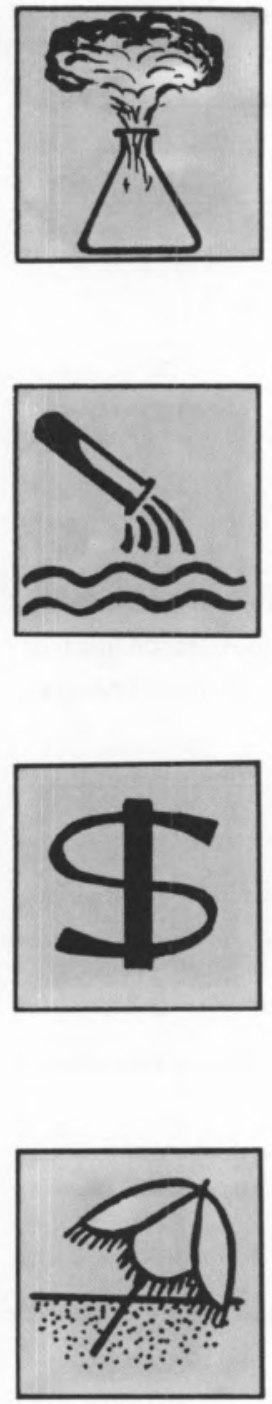

Até às primeiras horas da madrugada do dia 26 de Abril de 1986, Chernobyl foi uma cidade soviética como outra qualquer. Hoje, este nome entrou em todas as línguas: Chernobyl significa catástrofe nuclear.

Selecções do Reader's Digest, Março 1987

Na noite do incêndio da fábrica de Sandoz, em 31 de Outubro de 1986, toneladas de produtos químicos tóxicos foram derramados no Reno, provocando o maior desastre ecológico da história da Suíça.

Selecções do Reader's Digest, Outubro 1987

As centrais nucleares podem contribuir para o aumento de incidência de cancro no pulmão; contudo, a geração de energia através dos combustíveis fósseis é muito mais perigosa, podendo conduzir à morte prematura por doença nos brônquios. Mas qual é o político que se atreve a multar mais pesadamente a segunda do que a primeira?

Nature, 340,579(1989)

Pequenas bolas de crude, que se presume terem origem num petroleiro que procedia à lavagem dos seus depósitos ao largo da costa algarvia, espalharam-se pela praia de Faro.

Diário de Notícias, 30 Novembro 1989 


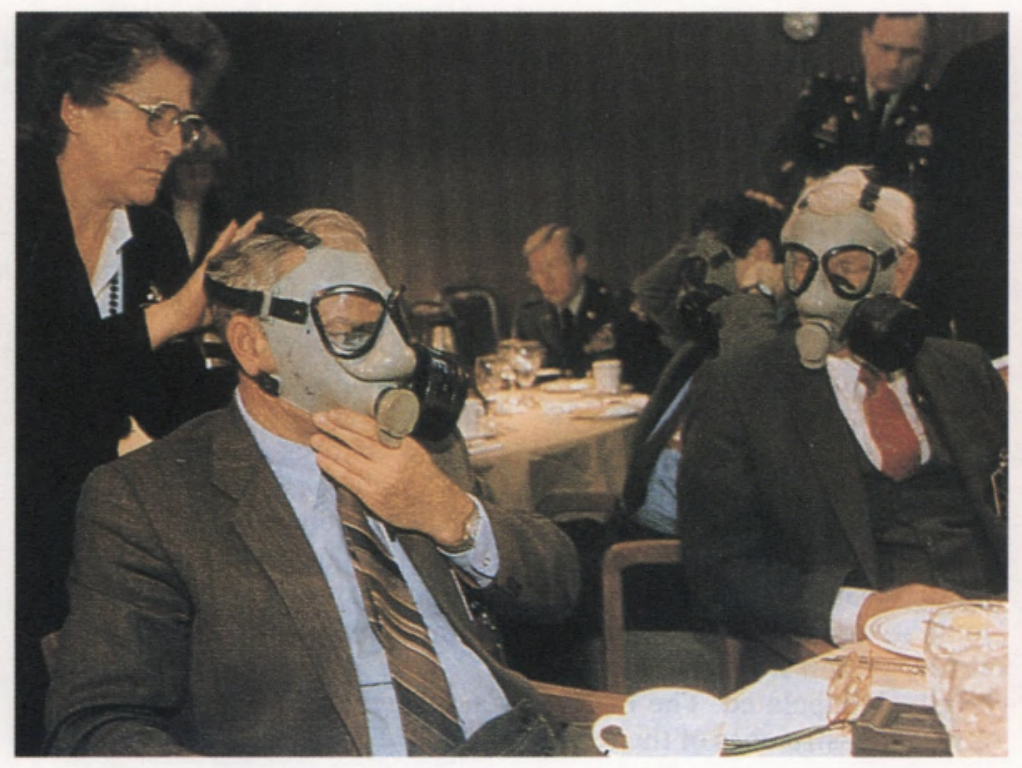

\section{Acidentes e Legislação}

Em termos de população activa, a Indústria Química em Portugal representa $3,5 \%$ e em termos de acidentes ronda os $20 \%$. Face a esta situação, a Federação dos Sindicatos da Química e Farmacêutica defende a actualização da legislação existente sobre higiene, segurança e reparação de acidentes no trabalho. A Federação classifica de positiva a legislação em vigor nos restantes países da CEE e considera urgente a sua aplicação em Portugal, através de regulamentação eficaz; considera, ainda, que há falta de informação no sector, designadamente no que respeita à perigosidade na utilização de substâncias químicas. 


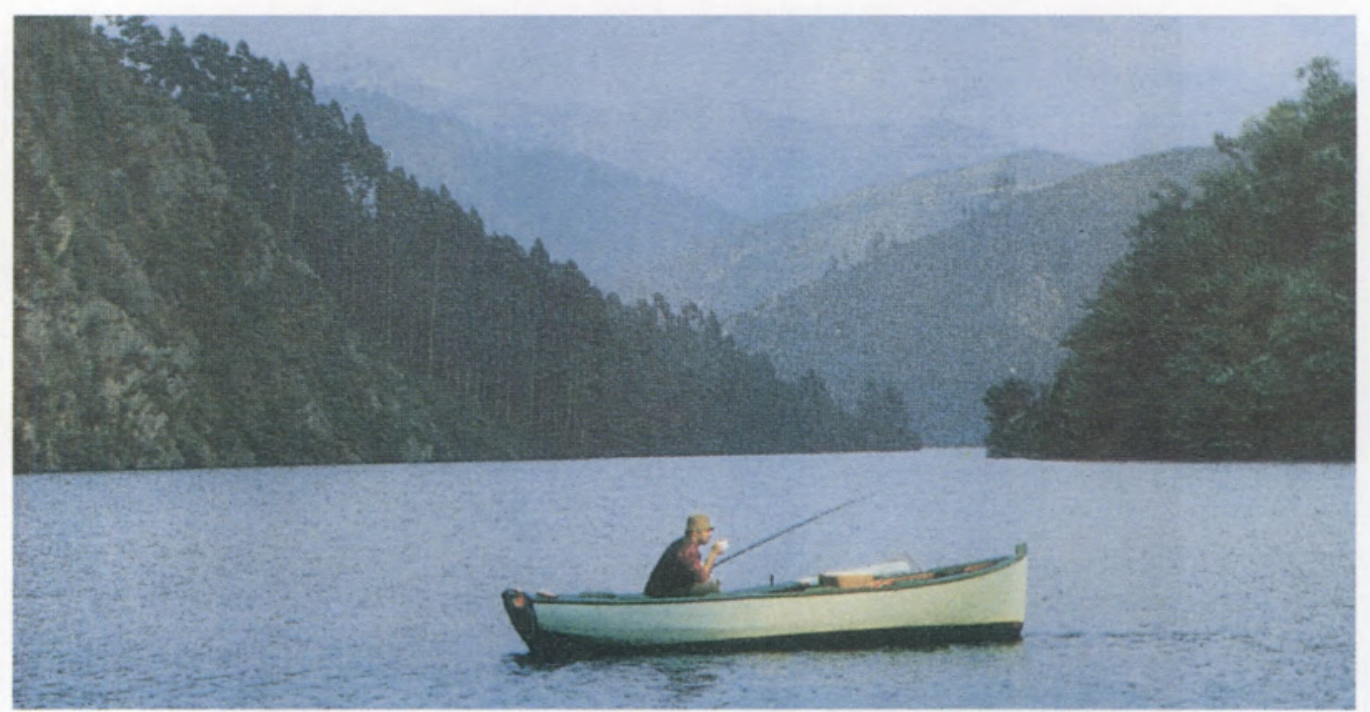

\section{Tecnologia: o Bem e o Mal}

A poluição e a destruição do meio ambiente não são, como poderíamos julgar, fenómenos apenas do século XX. (...) A tecnologia avançada não esteve na origem dos estragos causados ao meio ambiente em anos passados. A tecnologia de hoje, pelo contrário, tem sido utilizada para remediar várias formas de poluição natural e para limpar alguns dos problemas do passado - por exemplo, invertendo a situação em locais como lagos que foram declarados "mortos". Contudo, estes factos não servem para negar a gravidade dos problemas associados à indústria moderna. Segundo a revista "New Scientist", entre 1980 e 1985, só nos Estados Unidos, houve cerca de 7000 acidentes que envolveram produtos químicos tóxicos, incluindo explosões de gás. 